\title{
Endoscopic palliation for inoperable malignant dysphagia: long term follow up
}

\author{
V Maunoury, J M Brunetaud, D Cochelard, B Boniface, A Cortot, J C Paris
}

\begin{abstract}
This prospective non-randomised trial of 128 selected patients with unresectable oesophageal or gastrooesophageal junction cancers aims to evaluate the initial relief of malignant obstruction by means of bipolar electrocoagulation for both circumferential and submucosal strictures of $\mathrm{Nd}$ :YAG laser for the other patients. A limited dilatation was performed initially if a small calibre endoscope was unable to pass through the stricture. Prompt and significant relief of dysphagia without complications was achieved in $83 \%$ of patients. Improved patients were retreated monthly during the follow up period. Radiotherapy was recommended when possible. Symptomatic relief of obstruction lasted $\mathbf{4 \cdot 2}$ months on average and $76 \%$ of patients remained palliated until death. Monthly retreatment using the most appropriate endoscopic procedure for the tumour configuration and radiotherapy after endoscopic relief of obstruction seems to give the best palliation for patients with unresectable cancers of the oesophagus or gastrooesophageal junction.

(Gut 1992; 33: 1602-1607)
\end{abstract}

Patients with oesophageal squamous cell carcinomas or gastrooesophageal junction adenocarcinomas have a poor prognosis: five year survival being about $10 \% .{ }^{12}$ Surgical resection is the main curative treatment, but is limited to the early stages of disease. For other cases, various palliative treatments are available. The aim of these treatments is to restore and then to maintain a normal or almost normal food intake through the patient's survival. Dilatation, stents, Nd:YAG laser photocoagulation, bipolar electrocoagulation, and radiotherapy are the most commonly used techniques..$^{3-5}$ This work reports the results of a four year prospective study using dilatation, laser and/or bipolar electrocoagulation, and eventually radiotherapy in 128 patients (from January 1987 to December 1990) with nonsurgical and obstructive oesophageal or gastrooesophageal junction cancers.

de traitement par laser and Clinique des maladies de l'appareil digestif, Hopital C. Huriez, INSERM U 279 et Faculté de Pharmacie, Lille, France

V Maunoury

J M Brunetaud

D Cochelard

B Boniface

A Cortot

J C Paris

Correspondence to:

V Mounoury, MD, Centre multidisciplinaire de traitement par laser, S/sol aile traitement par laser, S/sol aile 59037 Lille Cedex, France. Accepted for publication 12 May 1992 balloons (Rigiflex TTS dilatators, Microvasive, Massachusetts, USA) passed through the biopsy channel of the endoscope. Savary-Gilliard dilatators (Bredam, Switzerland) or Eder-Puestow dilatators (Key Med, Southend on Sea, England), passed over a guide wire, were also used. The bipolar electrocoagulation tumour probe system is manufactured by CIRCON ACMI, Stamford, Connecticut, USA. The standard kit consists of five probes and a 50 watt bipolar generator. Four probes have a $360^{\circ}$ circumferential coagulation configuration and are $6,9,12$, and $15 \mathrm{~mm}$ in diameter. The fifth probe has an $180^{\circ}$ hemicircumferential configuration and is $15 \mathrm{~mm}$ in diameter. The probes are passed over a guide wire. It is very important to test the probe before treatment. The probe is connected to the generator and by putting a drop of saline on the metallic stripes and setting the generator dials at 3 with one second duration, boiling of the saline should be observed during stepping on the footpedal. A probe was not used for clinical application if it failed this test.

Two Nd:YAG lasers were used: the CILAS YM 101 (Marcoussis, France) and the Multilase 2500 of Technomed International (Paris, France). The laser beam was transmitted via a $400 \mu \mathrm{m}$ core non-contact fibre which was protected by a $1.6 \mathrm{~mm}$ teflon catheter and a $1.5 \mathrm{l} / \mathrm{min}$ nitrogen gas flow. The small diameter of the catheter allowed the gas to escape through the open biopsy channel of the Olympus GIF $Q$ endoscope (Tokyo, Japan) during laser treatment.

\section{CRITERIA FOR INCLUSION}

Before referral, all patients had a physical examination, routine laboratory tests, contrast swallow, chest radiograph and computed tomography (scan) of the chest and upper abdomen before and after oral contrast. Oesophagoscopy with biopsy was also performed to establish the tissue diagnosis. A bronchoscopy was performed in case of upper or middle third localisation of the oesophageal cancer. Swallowing function was evaluated with the following scale: 4 - unable to swallow anything, 3 - tolerates liquid diet, 2 tolerates soft diet, 1 - difficulty with some hard solids and 0 - tolerates normal diet.

All patients were deemed unsuitable for resection by a consulting surgeon because of the cancer stage or prohibitive operative risk. To qualify for endoscopic palliation, patients had to (a) have a significant dysphagia secondary to malignant obstruction, (b) not have tracheooesophageal fistula or invasion. of the tracheobronchial tree, (c) not have significant extrinsic compression, (d) have an expected survival of $>30$ days ('performance status grading' $<3$,' (e) have strictures allowing passage of a small calibre endoscope (Olympus XQ), after dilatation if necessary.

Before endoscopic therapy, oesophagoscopy was performed again to evaluate (i) the need for dilatation if a small calibre endoscope was unable to pass through the stenosis, (ii) the circumferen- 
tial extention of the cancer and (iii) the configuration of the tumour (exophytic or submucosal). Patients with roughly uniform circumferential stenosis (both circumferential and submucosal tumour) were included in the bipolar electrocoagulation group and patients with exophytic nodules obstructing the lumen were included in the laser group.

\section{DILATATION}

If needed, dilatation was performed the day before laser or bipolar electrocoagulation treatment using dilatators of increasing sizes up to the diameter allowing easy passage of a small calibre endoscope. We usually started with through the endoscope dilatation balloons of 8 to $12 \mathrm{~mm}$ in diameter. Then, a guide wire could be placed in the stomach using the small calibre endoscope and Savary dilatators of 11 or $12.8 \mathrm{~mm}$ in diameter were finally passed through the stricture to complete the first dilatation obtained with balloons. If balloon dilatation was not feasible, the guide wire was passed through the malignant stricture endoscopically and its placement checked fluoroscopically before using SavaryGilliard dilatators under fluoroscopic guidance. Eder-Puestow probes of 33 or 39 French gauge were used for short and very tight stenoses.

\section{INITIAL TREATMENT: LASER GROUP}

Outpatients were treated without sedation. In some patients dilatation was needed initially to allow passage of the $10 \mathrm{~mm}$ endoscope. Laser treatment was performed from the distal to the proximal part of the tumour. The Nd:YAG laser was used to coagulate (whiten) the tumour. Coagulation necrosis without unexpected delayed slough was obtained by using $40 \mathrm{~W}$ of power, a $2 \mathrm{~mm}$ spot size $\left(1200 \mathrm{~W} / \mathrm{cm}^{2}\right.$ and one second-exposure. Air was aspirated from the stomach at the end of each endoscopic procedure. During initial treatment, patients were treated twice weekly until photodestruction of all the exophytic parts of the tumour was achieved.

\section{INITIAL TREATMENT: BIPOLAR}

\section{ELECTROCOAGULATION GROUP}

The initial treatment was usually performed during a three day hospitalisation. Stricture dilatation was performed as necessary on the first day. Bipolar electrocoagulation treatment was carried out on the second day under diazepam premedication. At first, we passed the small endoscope through the stricture, recording the location of its proximal and distal margins in centimetres from the incisors, to place the guidewire into the stomach. The endoscope was then removed and the largest tumour probe that could easily go through the dilated stricture without significant resistance was passed over the guidewire. Usually the tumour probe size approximated the diameter of the dilatator that had been used to dilate the stricture. Most often these were the 9 or $12 \mathrm{~mm}$ diameter $360^{\circ}$ circumferential probes. The probe was passed to the top of the stricture using the centimetre marks of its handle and the mild resistance encountered as it engaged
TABLE I Reasons for exclusion of 63 patients

\begin{tabular}{|c|c|c|c|}
\hline & $\begin{array}{l}\text { Laser } \\
\text { group }\end{array}$ & $\begin{array}{l}\text { BICAP } \\
\text { group }\end{array}$ & Total \\
\hline Referred for other treatments & 12 & 2 & 14 \\
\hline Fit for surgery & 8 & 2 & \\
\hline Radiotherapy (no dysphagia) & & 0 & \\
\hline Life expectancy $<30$ days & 9 & 13 & 22 \\
\hline Dilatation not feasible & 4 & 11 & 15 \\
\hline Tracheooesophageal fistula or & & & \\
\hline invasion of the respiratory tree & 3 & 6 & 9 \\
\hline Extrinsic compression & 1 & 2 & 3 \\
\hline Total & 29 & 34 & 63 \\
\hline
\end{tabular}

$\mathrm{BICAP}=$ bipolar electrocoagulation.

TABLE II Reasons for inclusion of 128 patients

\begin{tabular}{|c|c|c|c|}
\hline & & $(n)$ & $\%$ \\
\hline $\begin{array}{l}\text { Unsuitable for resection } \\
\text { Non-surgical candidate } \\
\text { Metastasis } \\
\text { Local extension }\end{array}$ & $\begin{array}{l}49 \\
31 \\
19\end{array}$ & 99 & 77 \\
\hline $\begin{array}{l}\text { Incomplete remission after } \\
\text { radiotherapy } \\
\text { Recurrence after: }\end{array}$ & & $\begin{array}{l}11 \\
18\end{array}$ & $\begin{array}{r}9 \\
14\end{array}$ \\
\hline $\begin{array}{l}\text { Radiotherapy } \\
\text { Surgery }\end{array}$ & $\begin{array}{r}11 \\
7\end{array}$ & & \\
\hline
\end{tabular}

the proximal portion of the stricture. Placement of the probe was checked before coagulation by passing a small endoscope alongside the probe. On the bipolar electrocoagulation generator, the dial setting used was 10 with a pulse duration of two seconds. Five pulses were delivered and the probe then advanced to the next position as determined by the probe stripe length. Antegrade coagulation was undertaken until the distal margin of the stricture was reached, using the distance recorded during the preceding endoscopy. On the third day, the stricture was examined endoscopically for completeness of coagulation and for a complementary laser photocoagulation of any exophytic area that did not appear well coagulated in a few cases. Patients were then discharged with the recommendation to chew their food well and to swallow it with a lot of water.

FOLLOW UP

Patients were reexamined routinely two weeks after the end of the initial treatment to evaluate their functional improvement. Then, patients with initial improvement were reendoscoped monthly to be retreated with dilatation, laser, or bipolar electrocoagulation on the basis of the endoscopic cancer configuration at follow-up. External beam radiotherapy with or without chemotherapy was recommended in patients with squamous cell carcinoma without metastasis unless these therapies had been given previously.

\section{PATIENTS}

One hundred and ninety seven patients with dysphagia secondary to a malignant obstruction were referred to us from January 1987 to December 1990 . Sixty nine (35\%) were excluded from this trial: 63 did not fit the criteria for inclusion (Table I). Six others were also excluded: one patient had an endoprosthesis, two patients were operated on after first relief of obstruction with endoscopic treatment and the last three patients were only dilated because of persistent necrosis after radiotherapy. 


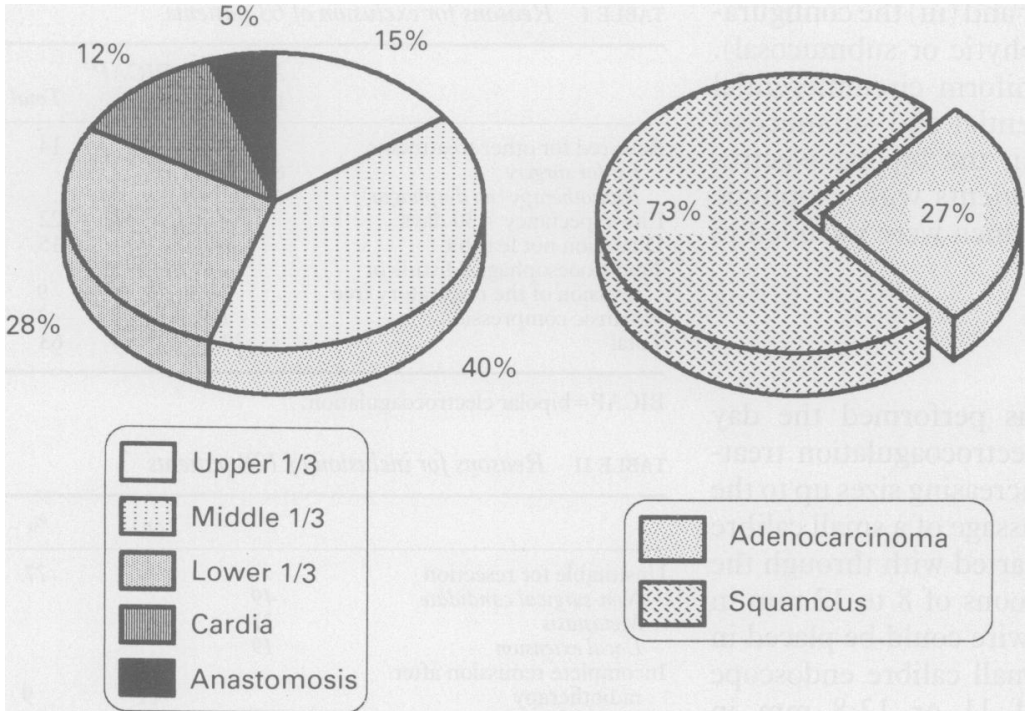

Figure 1: Location and histology of the cancer in 128 patients.

One hundred and twenty eight patients (13 females) with an average age of 64 years (range 35-91) were included in this trial. Ninety patients were included in the laser group and 38 patients in the bipolar electrocoagulation group. Ninety nine patients were not suitable for surgery and endoscopic therapy was the first treatment, 11 patients had a persistent malignant obstruction after radiotherapy and 18 had a recurrence after radiotherapy or surgery (Table II). Eight patients had a jejunostomy after surgical exploration which revealed that the cancer was unsuitable for resection. Figure 1 shows the location and the histology, Figure 2 the annular size of the tumour base of cancers. The initial mean dysphagia grade was $2 \cdot 7(0 \cdot 1)(\mathrm{SE}): 2,4$ in the laser group and 3,4 in the bipolar electrocoagulation group.

\section{EVALUATION}

Success of initial treatment was defined as improvement to grade 2 or better during a minimum period of 15 days without retreatment. The maximum improvement in dysphagia grade for each patient was noted. Four factors were studied by multivariate analysis for a possible effect on initial results: reason for treatment, location, histology, and circumferential exten-

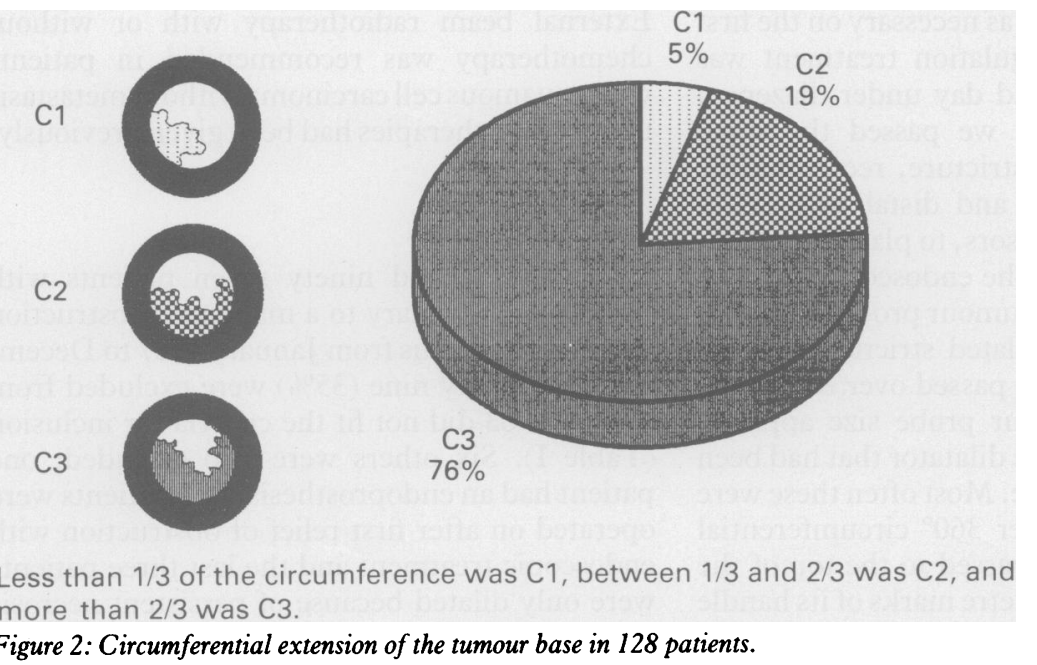

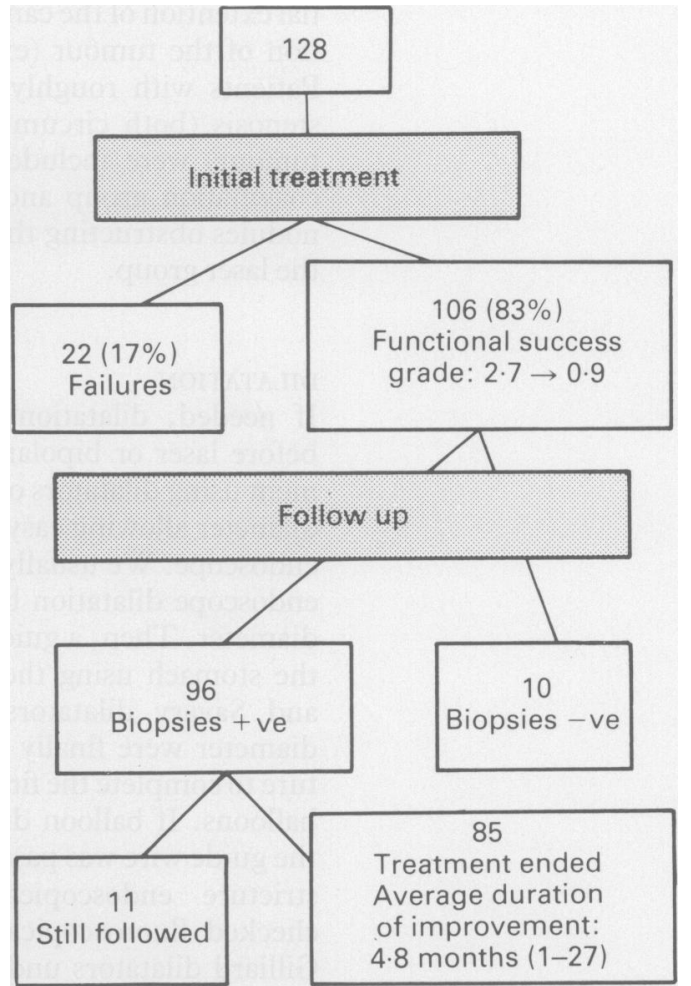

Figure 3: Results in 128 patients.

sion of the cancer. Statistical analysis was performed separately for the laser group and bipolar electrocoagulation group. Survival and duration of improvement for patients with successful initial treatment were studied by life table analysis. Reasons for discontinuing treatment were noted. The above four factors plus radiotherapy were studied by step by step regression analysis for a possible effect on duration of improvement (bipolar electrocoagulation group and laser group studied together).

\section{Results}

Figure 3 shows the initial and long term results.

\section{INITIAL RESULTS}

Nineteen patients (21\%) of the laser group and 37 (97\%) patients of the bipolar electrocoagulation group were initially dilated. Three patients of the bipolar electrocoagulation group had a comple-

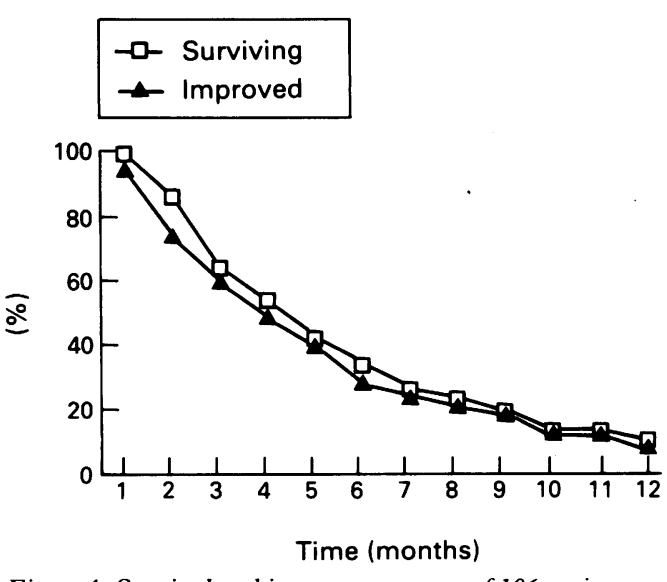

Figure 4: Survival and improvement rates of 106 patients with a functional success, by life table analysis. 
TABLE III Average duration of improvement in the 85 patients with an ended treatment, in function of the adjuvant radiation therapy

\begin{tabular}{|c|c|c|c|c|}
\hline & \multicolumn{2}{|c|}{$\begin{array}{l}\text { Without adjuvant } \\
\text { radiotherapy }\end{array}$} & \multicolumn{2}{|c|}{$\begin{array}{l}\text { With adjuvant } \\
\text { radiotherapy }\end{array}$} \\
\hline & $\bar{n}$ & $A D I$ (range) & $n$ & $A D I$ (range) \\
\hline $\begin{array}{l}\text { Laser group } \\
\text { BICAP group }\end{array}$ & $\begin{array}{l}51 \\
19\end{array}$ & $\begin{array}{c}4 \cdot 5 \mathrm{mo}(1-16) \\
3 \mathrm{mo}(1-8)\end{array}$ & $\begin{array}{l}8 \\
7\end{array}$ & $\begin{array}{l}7 \cdot 7 \mathrm{mo}(3-21) \\
6 \cdot 4 \mathrm{mo}(1-27)\end{array}$ \\
\hline
\end{tabular}

$\mathrm{ADI}=$ average duration of improvement.

TABLE IV Reasons for discontinuing treatment in 85 patients with initial improvement

\begin{tabular}{lrll}
\hline & & $n$ & $\%$ \\
\hline $\begin{array}{l}\text { Died without oesophageal obstruction } \\
\quad \text { from cancer }\end{array}$ & 60 & 64 & 76 \\
$\quad$ from other cause & 4 & & \\
Lost to follow up & & 1 & 1 \\
Poor tolerance & 4 & 5 \\
Required gastrostomy & 8 & 9 \\
Required prosthesis & 8 & 9 \\
\hline
\end{tabular}

mentary laser treatment the day after treatment. Initial treatment failed to improve 22 patients (17\%): $17(19 \%)$ in the laser group and five (13\%) in the bipolar electrocoagulation group. Eight patients were treated only once and the 14 others had 1.9 treatments on average, failure of treatment being assumed an average of 22 days later.

One hundred and six patients $(83 \%)$ improved: $81 \%$ after a mean of $2 \cdot 3$ treatments (range $1-4$ ) and one week in the laser group, $87 \%$ after a single treatment and three days in the bipolar electrocoagulation group. Average dysphagia grade rose from 2.7 to 0.9 for improved patients: from 2.4 to 0.8 in the laser group and from 3.4 to $1 \cdot 1$ in the bipolar electrocoagulation group.

Figure 5: Influence of circumferential extension of the tumour base on duration of improvement, by life table analysis. $p$ value is according to global test.
Figure 6: Influence of adjuvant radiotherapy on duration of improvement, by life table analysis.
No failure occurred in the laser group patients with a $\mathrm{Cl}$ tumour or treated for persistent malignant obstruction after previous radiotherapy. For the 72 other patients of the laser group, the success rate was significantly lower $(p<0.05)$ in patients with a recurrence after surgery or radiotherapy (four of seven) than in the others (13/65). Failures also occurred more often for cancers located in the upper third of the oesophagus (four of nine) or at an anastomosis (three of six) than in the others (10/57). In the bipolar electrocoagulation group, no failure occurred in upper or middle third lesions. The failure rate was higher in patients with an adenocarcinoma (four of nine) when compared with those with a squamous cancer (one of 29), $\mathrm{p}<0 \cdot 01$.

\section{LONG TERM RESULTS}

Figure 4 shows the survival and improvement curves of initially improved patients. Complete destruction of the tumour was obtained in 10 patients with negative biopsies on follow up (three $\mathrm{Cl}$, two $\mathrm{C} 2$ and five $\mathrm{C} 3$ cancers). All had radiotherapy (associated with chemotherapy in two cases), after relief of dysphagia with endoscopic therapy. A local recurrence occurred in three patients, 10 months later on average. Two patients died, one from metastasis at five months and one from a stroke at one month. The five other patients are still under follow up (five months follow up on average) without recurrence of the cancer.

Eleven patients with persistent disease are still receiving treatment and remain improved. Three had radiotherapy and chemotherapy. Endoscopic treatment has been completed in 85 patients. During follow up, 83 had one or more sessions of endoscopic treatment $(3 \cdot 1$ sessions in average): 42 patients were dilated, 76 were treated with laser and 20 with bipolar electrocoagulation. Fifteen also had radiotherapy with chemotherapy as well in three cases. The average duration of improvement was $4 \cdot 8$ months (range 1-27). Table III gives the duration of improvement for the laser group and bipolar electrocoagulation group, with or without radiotherapy. Reasons for discontinuing treatment are given in Table IV.

Improvement duration was significantly related to the circumferential extension of the tumour base (Fig 5). The recommendation for radiotherapy after relief of obstruction with endoscopic therapy was associated with a longer duration of improvement (Fig 6).

\section{COMPLICATIONS}

Four hundred and seventy sessions of laser treatment and 75 sessions of bipolar electrocoagulation treatment were performed. No complications occurred during initial treatment. Two complications occurred during the follow up period: a tracheooesophageal fistula after endoscopic therapy with bipolar electrocoagulation and laser in a patient previously treated by radiotherapy, needing endoprosthesis placement, and an haemorrhage requiring blood transfusion after bipolar electrocoagulation treat- 
ment. Thus, the complication rate was $1 \cdot 5 \%$ without mortality.

\section{Discussion}

The vast majority of patients with obstructing oesophageal or gastrooesophageal junction carcinomas are not curable by the time of presentation and few survive beyond one year. ${ }^{7}$ Such patients may benefit from palliative therapy, however, which aims to allow an almost normal food intake until death. From this point of view, palliative treatment has to be not only quickly effective but also well tolerated, without prolonged hospital stay and with a low rate of complications. This study aimed to evaluate in a non-randomised prospective trial the initial relief of malignant obstruction by means of laser or bipolar electrocoagulation with a previous dilatation if necessary. We also studied the long term follow up palliation with repeated endoscopic treatments using the same endoscopic procedures and radiotherapy if recommended.

Like Jensen, ${ }^{8}$ we do not think that all referred patients necessarily benefit from endoscopic $\mathrm{Nd}$ :YAG or bipolar electrocoagulation tumour probe treatment. We excluded 69 patients $(35 \%)$ : 14 were referred for a more appropriate treatment because they did not have a true dysphagia or could be operated on. Patients were referred to us for palliation and this is the origin of the small number of candidates for surgery or radiotherapy. Twenty two patients were not treated because of their poor general condition. Mellow ${ }^{6}$ showed that poor performance status (including severe anorexia) at accession is correlated with poor functional outcome. Twenty seven cancers were deemed unsuitable for endoscopic procedures because of (a) a non-dilatable stenosis which did not permit a safe thermal treatment ${ }^{9}$ and so were treated with jejunostomy, (b) a fistula or extrinsic compression and so were treated with endoprosthesis. The last six patients were excluded for miscellaneous causes as already described.

Routine upper gastrointestinal endoscopies are performed in our hospital without sedation. With our parameters, laser application is not painful by itself. Thus, laser treatments were carried out without sedation. Sedation was used for bipolar electrocoagulation treatments because the procedure was more uncomfortable, requiring the successive placements of a guidewire, a rigid bipolar electrocoagulation probe with a semi rigid handle, and a small endoscope.

Prompt relief of obstruction without complications and prolonged hospitalisation was achieved in most patients (83\%). Fifty six (43\%) had dilatation during initial treatment. It is assumed that through the scope balloon dilatation is effective for treating complex malignant strictures. ${ }^{10}$ Its main advantages are dilatation under endoscopic guidance with the forces applied radially. After balloon dilatation, a small calibre endoscope can be passed through the stricture, and this facilitates guide wire placement for subsequent Savary dilatation needed to reinforce the balloon dilatation. Using this careful and limited in diameter method of dilatation (11 to $12.8 \mathrm{~mm}$ ), no complications occurred in our series at this initial stage of the treatment. Such dilatation of tight malignant strictures did not aim to really improve dysphagia but was only considered as the first step of the endoscopic treatment, "12 before thermal treatment.

Laser treatment of malignant oesophageal obstruction is an effective method for palliation of dysphagia. It is usually well tolerated and can be performed in outpatients. ${ }^{42}$ Our retrograde method using non-contact fibres and low irradiance is as effective as vaporisation with high irradiance. $^{+4}$ Indeed, our improviement rate $(81 \%)$ is equal or higher than the rates of $69 \%$ to $86 \%$ reported in eight series with a minimum of 30 patients treated with high irradiance. ${ }^{261217}$ Usual parameters found in the literature which influence the initial success rate adversely are (a) a tumour length $>5 \mathrm{~cm},{ }^{3}$ (b) a complex stricture at the gastrooesophageal junction," (c) a submucosal tumour ${ }^{3}$ and (d) an upper third location. ${ }^{3612}$ In our opinion, a contrast swallow and endoscopic examination give a poor indication of the length of tumour or stricture. Thus, we did not look at this parameter even if we agree that long stenoses are more difficult to treat. In our laser group, the factor indicating bad prognosis was laser treatment for a recurrence, contrary to Rutgeerts experience. ${ }^{17}$ Upper third and anastomotic lesions tended to badly influence the success rate.

The bipolar electrocoagulation tumour probe is well adapted to the treatment of long, submucosal, circumferential and tight malignant strictures. ${ }^{518}$ Thirty eight patients with such a tumour configuration were treated with the bipolar electrocoagulation probe. The success rate $(87 \%)$ is similar to that $(86 \%)$ of Jensen's series. ${ }^{8}$ The depth of coagulated tissue depends on forces applied radially by the probe. ${ }^{19}$ So we used the largest tumour probe that could be passed through the stricture. Two to $4 \mathrm{~mm}$ of coagulation is usually achieved. Therefore, after the slough of radially coagulated tissue in a circumferential stricture, the luminal diameter may increase by 4-8 $\mathrm{mm}$ compared with the pretreatment size. ${ }^{8}$ Failures occurred only in patients with lower third, cardia, and anastomotic lesions. This correlates with a higher failure rate in adenocarcinomas than in squamous cancers. The bipolar electrocoagulation probe is not well adapted to distal, rugged, or angulated strictures.

Fistulae and haemorrhages have been reported with a rate of $4 \%$ to $20 \%$ in the laser series, ${ }^{3612} 17$ and $20 \%$ using the bipolar electrocoagulation. Thermally induced fibrous stenosis occurred in $12.5 \%$ of the cases in another bipolar electrocoagulation series. ${ }^{20}$ In our experience, no complications occurred during initial treatment in laser and bipolar electrocoagulation groups and only two complications occurred during the follow up period. The goal of our palliative treatment using laser or bipolar electrocoagulation was to achieve a limited recanalisation allowing an almost normal food intake and not to completely destroy the full thickness of the tumour. This could explain our low complication rate for both techniques. Our laser technique is safe because we limit the effect to retrograde coagulation at low irradiance. The bipolar 
electrocoagulation procedure in selected tumour strictures using a small calibre tumour probe (9 or $12 \mathrm{~mm}$ ) and careful application under endoscopic guidance avoiding inappropriate treatment at the tumour margins minimise the risks of complications previously reported in the literature.

Symptomatic relief persists for four to 10 weeks after successful treatment with laser or bipolar electrocoagulation. ${ }^{81317}$ This led us to carry out a new endoscopy monthly during the follow up period for the initially improved patients with a new treatment in most cases. In addition, $26 \%$ of these patients had radiotherapy. This approach was well accepted by the patients and only $6 \%$ were lost to follow up. Symptomatic relief persisted 4.2 months on average. Seventy six per cent remained improved until death. The two complications occurred during this period in multitreated patients. Endoscopic retreatments were adapted to the configuration of the malignant obstruction. The efficacy of laser treatment tends to decrease when submucosal tumour spreads ${ }^{17}$ and patients are then better treated by the bipolar electrocoagulation. On the other hand, laser treatment is often needed to treat exophytic margins of malignant strictures after initial successful bipolar electrocoagulation treatment. Thus, we have combined the laser group and the bipolar electrocoagulation group for studying the duration of improvement. Retreating patients with the laser and/or the bipolar electrocoagulation appears to be better than the placement of an endoprosthesis after initial successful thermal treatment: in a prospective randomised trial of laser therapy only and laser therapy followed by endoscopic intubation, a lower rate of complications and a better improvement of dysphagia was found in the laser only group. ${ }^{21}$ When retreatments stop being efficient, however, we share Bown's opinion that endoscopic intubation is a fallback position if full dilatation is still possible. ${ }^{22}$

The length of time that symptomatic relief persists is difficult to evaluate because few studies report standardised follow up data. In Rutgeerts's series, ${ }^{17}$ duration of laser palliation averaged 11 weeks and palliation until death was obtained in $62 \%$ of patients. In Naveau's study, ${ }^{16}$ the cumulative probabilities of remaining improved at three and six months in patients initially treated with success were $38.5 \%$ and $22 \%$. In our series, the average duration of improvement was 17 weeks and the same probabilities were $60 \%$ and $29 \%$. The importance of initial improvement and an adenocarcinoma were positively correlated with the duration of improvement in Naveau's series and the initial tumour length was negatively correlated. The longer duration of improvement in our series may be the result of monthly retreatment with various procedures and to radiotherapy when it was possible. In our series, the initial extension of annular size of the tumour base and adjuvant radiotherapy were the two factors influencing improvement of duration. The positive influence of adjuvant radiotherapy was also found in a recent pilot study which suggested a trend towards longer survival in patients treated with laser followed by radiation compared with laser alone ${ }^{23}$ although neither series gave a randomised comparison, and the patients treated by radiotherapy had less advanced disease than those who were not.

Laser treatment provides good palliation in the majority of patients with unresectable oesophageal or gastrooesophageal junction cancers. The bipolar electrocoagulation tumour probe offers a palliative solution for the minority of patients with submucosal, circumferential and tight malignant stricture. These procedures were well tolerated and associated with low morbidity while following our method in selected patients. The long term maintenance of improvement is positively influence by a monthly repeated treatment using the best procedure for the tumour configuration. Radiotherapy may be of value for some patients to slow down tumour regrowths after endoscopic relief for obstruction.

1 Earlam R, Cunha-Melo JR. Oesophageal squamous cell carcinoma: a critical review of surgery. Br $\mathcal{F}$ Surg $1980 ; 67$ 381-90.

2 Bizer L. Adenocarcinoma of the stomach: current results of treatment. Cancer 1983; 51 : 743-9.

3 Fleischer D, Sivak M. Endoscopic Nd:YAG laser therapy as palliation for oesophagogastric cancer. Gastroenterology 1985; 89: 827-31.

4 Jensen DM. Palliation of esophagogastric cancer via endoscopy. Gastroenterol Clin Biol 1987; 11: 361-3.

5 Johnston JH, Fleisher D, Petrini J, Nord HJ. Palliative bipolar electrocoagulation therapy of obstructing esophageal cancer. Gastrointest Endosc 1987; 33: 349-53.

6 Mellow MH, Pinkas H. Endoscopic laser therapy for malignancies affecting the esophagus and gastroesophageal juncnancies affecting the esophagus and gastroesophageal juncMed 1985; 145: 1443-6.

7 Akiyama H, Tsurumaru M, Watanebe G, Ono Y, Suzuki M Development of surgery for carcinoma of the esophagus Am F Surg 1984; 147: 9-16.

8 Jensen DM, Machicado G, Randall G, An Tung L, EnglishZych S. Comparison of low-power YAG laser and Bicap tumor probe for palliation of esophageal cancer strictures. Gastroenterology 1988; 94: 1263-70.

9 Maunoury V, Brunetaud JM, Cochelard D, Delette O, Corto A, Paris JC. Traitement palliatif des cancers de l'oesophage et due cardia par photoablation laser. Gastroenterol Clin Biol 1987; 11: 371-5.

10 Graham DY, Tabihian N, Schwartz JT, Lacey Smith J. Evaluation of the effectiveness of through-the-endoscope Evaluation of the effectiveness of through-the-endoscope intestinal strictures. Gastrointest Endosc 1987; 33: 432-5.

11 Riemann JF, Ell Ch, Lux G, Demling L. Combined therapy of malignant stenoses of the upper gastrointestinal tract by means of laser beam and bougienage. Endoscopy 1985; 17 43-8.

12 Lightdale CJ, Zimbalist E, Winawer SJ. Outpatient management of esophageal cancer with endoscopic Nd:YAG laser. Am F Gastroenterol 1987; 82: 46-50.

13 Bown SG, Hawes R, Matthewson K, Swain CP, Barr $\mathrm{H}$ Boulos PB, et al. Endoscopic laser palliation for advanced malignant dysphagia. Gut 1987; 28: 799-807.

14 Schulze S, Fischerman K. Palliation of oesophagogastric neoplasms with Nd:YAG laser treatment. Scand $\mathcal{F}$ Gastroenterol 1990; 25: 1024-7.

15 Krasner N, Barr H, Skidmore C, Morris AI. Palliative laser therapy for malignant dysphagia. Gut 1987; 28: 792-8.

16 Naveau S, Chiesa A, Poynart T, Chaput JC. Endoscopic $\mathrm{Nd}$ :YAG laser therapy as palliative treatment for esophagea and cardial cancer: parameters affecting long term outcome. Dig Dis Sci 1990; 35: 294-301.

17 Rutgeerts P, Vantrappen G, Broeckaert L, Muls M, Geboes K, Coremans G, et al. Palmiative Nd:YAG laser therapy fo cancer of the esophagus and gastroesophageal junction: impact on the quality of remaining life. Gastrointest Endos 1988; 34: 87-90.

18 Fleischer D. A comparison of endoscopic laser therapy and Bicap tumor probe therapy for esophageal cancer. Am f Gastroenterol 1987; 82: 608-12.

19 Laine L. Determination of the optimal technique for bipolar electrocoagulation treatment. Gastroenterology 1991; 100 : electroc 107 .

20 Fleischer D, Ranard R, Kamarth R, Bitterman P, Benjamin S. Stricture formation following Bicap tumor probe therapy for esophageal cancer. Clinical observation and experimental studies [Abstract]. Gastrointest Endosc 1987; 33: 183.

21 Barr H, Krasner N, Raouf A, Walker RJ. Prospective randomised trial of laser therapy only and laser therapy followed by endoscopic intubation for the palliation of malignant dysphagia. Gut 1990; 31: 252-8.

22 Bown G. Palliation of malignant dysphagia: surgery, radiotherapy, laser, intubation alone or in combination? Gut 1991; 32: 841-4.

23 Loizou LA, Tobias J, Blackman G, Grigg D, Sargeant IR, Bown SG. Combined Nd YAG laser phototherapy and external beam radiotherapy for the paliation of advanced malignant dysphagia. $\operatorname{Br} \mathcal{F}$ Cancer 1990; 62 (suppl XI): 28 . 